\title{
Crítica literaria
}

In Cres. Vol. $3 N^{\circ}$ 2: pp. 359-364, 2012

\section{INDAGACIÓN SOBRE TEXTOS CHIMBOTANOS*}

\author{
Ricardo Ayllón ${ }^{(l)}$
}

\section{LA SOLEDAD DE SIGFRIDO, de Antonio Sarmiento}

El poeta chimbotano de larga residencia en el Callao, Antonio Sarmiento, vuelve a la carga con este nuevo libro en el cual, fiel a su espíritu irónico y desmitificador, ofrece algunos de los componentes de ese posmodernismo expresivo que impregnó a la poesía de su generación, aquella que tuvo que asimilar los referentes relativistas que comenzaron a definir los contextos creativo y teórico de fines de los años ochenta. Ficcionando y tomando como premisa los nuevos prejuicios culturales alimentados por la tecnología virtual, el autor nos remite a una 'intriga cultural' donde la Internet toma parte importante, poniendo como telón de fondo las controversias y divagaciones sobre el ocaso del libro.

En el centro de esta vorágine contemporánea, relumbra el libro de Andrea, poeta limeña a quien Sarmiento da vida para resolver la inquietud de sus intimidades temáticas a partir de un desarrollo cadencioso y altamente expresivo. La soledad de Sigfrido

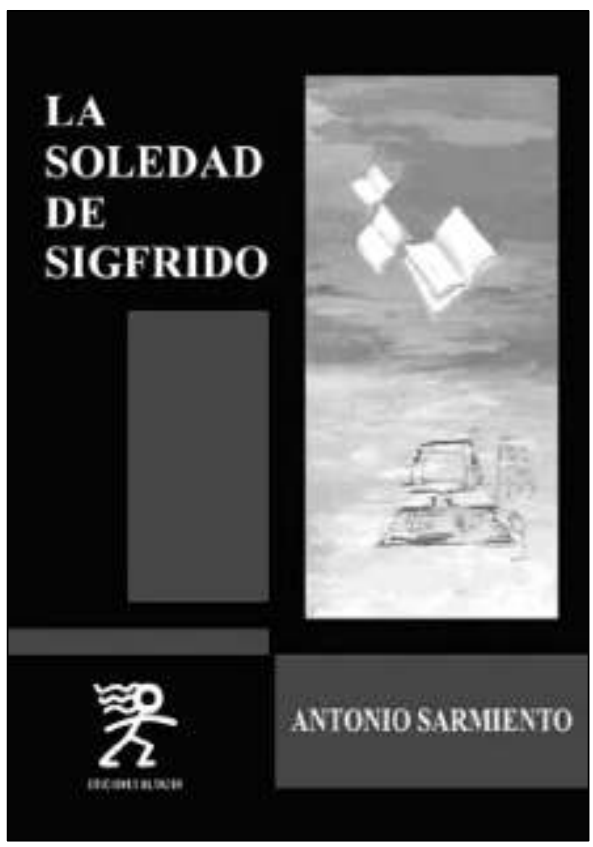

* Recibido: 10 de julio del 2012; aprobado: 13 de diciembre del 2012.

(1) Abogado. Universidad Nacional Mayor de San Marcos. Poeta, narrador y editor. Director de Ornitorrinco Editores. 
(Altazor, 2010) nos entrega a un Sarmiento que parecía haber ofrecido sus principales hallazgos discursivos, pero que ahora, con este registro maduro y versátil, da cuenta de un proceso lírico que aspira a la plenitud creativa.

\section{TRAZO DEL TIEMPO. VIÑETAS, de Amarildo Obeso Sánchez}

Reconocido ya en el ámbito local no solo por la calidad de su plástica sino también por su trabajo consecuente en la docencia y la promoción cultural, el artista Amarildo Obeso sorprende incursionando en el terreno editorial a través de un opúsculo que reúne dibujos monocromáticos, de trazo fino y fuerte carga surrealista. Según el texto introductorio de la publicación, estas viñetas fueron planteadas inicialmente para el libro Confidencia bajo sombra, del poeta chimbotano Elmer Coral, lo que hace asumir que esta sea la razón por la cual cada viñeta venga acompañada de unos versos.

El artista se ha servido, en su generalidad, de rasgos humanos para plantear sus temas, con un discurso visual donde los personajes parecen asaltar el naturalismo inicial y ser condescendientes con la condición humana del observador. Es lamentable, sin embargo, que la impresión de las viñetas sea un tanto difusa y éstas no se aprecien en su real magnitud. Aún así saludamos la edición de Trazo del tiempo (edición del autor, 2011), pues gracias a ella las particularidades estéticas e imaginación de Obeso Sánchez llegan a más espectadores.

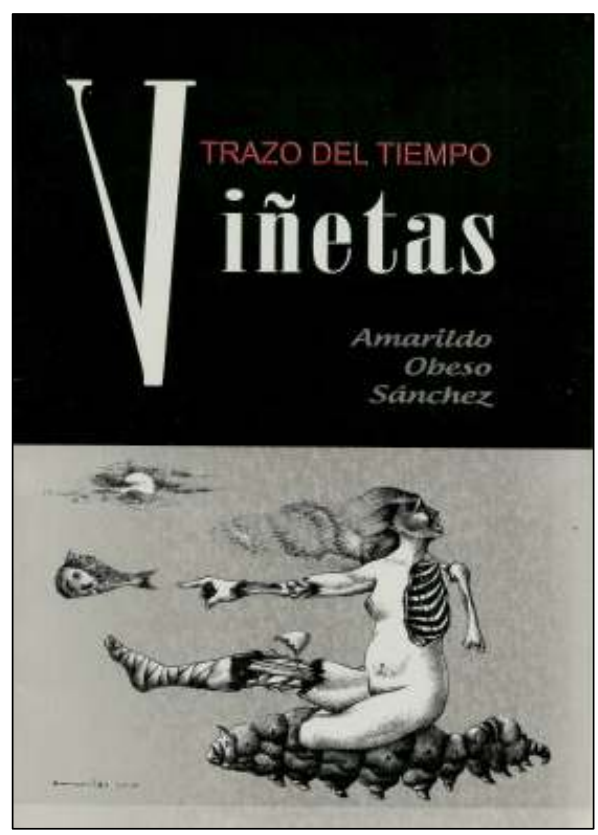

\section{EL ECO DE UN PANTANO, de Mateo Durand Huachuronto}

Este es el inicio de uno de los más acariciados sueños del docente Mateo Durand: el de proyectarse a la comunidad chimbotana para crear consciencia de la urgencia de salvaguardar aquel santuario natural llamado Pantano de Villa María. Pese a que se encuentra justo en el centro de la provincia (y quienes nos trasladamos con frecuencia de Chimbote a Nuevo Chimbote lo vemos y respira- 
mos siempre), este pequeño pero importante hogar de aves, peces y plantas pasa desapercibido para la mayoría de chimbotanos.

Es por ello que Durand ha considerado que, si de crear consciencia se trata, hay que dirigirse a ese ser humano que todavía puede escuchar con atención y conseguir que prenda en su corazón un desinteresado amor por la naturaleza que es el niño, quien conocerá las causas de la contaminación de los humedales y la forma como aún puede brindarles una esperanza de vida. El eco de un pantano (Ornitorrinco, 2011) presenta un lenguaje sencillo y ésta es quizá la principal ventaja de su contenido. Ojalá llegue al corazón de nuestros ciudadanos y sea el inicio de una verdadera cruzada para la preservación de nuestro patrimonio natural.

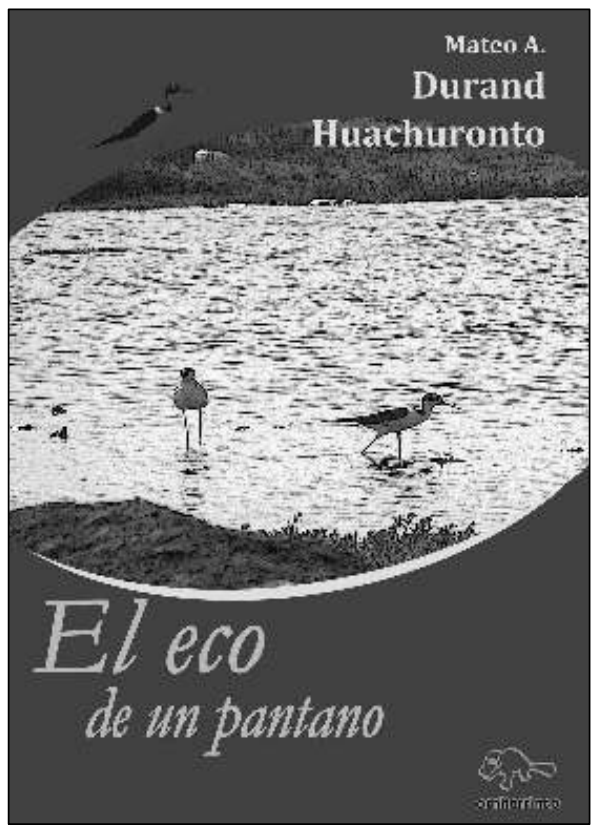

\section{HOMBRES DE MAR, de Óscar Colchado Lucio}

Luego de la aparición del libro de cuentos Del mar a la ciudad, en la década del '80, y del volumen infantil Rayito y la princesa del médano (2009) -veinte años después-, parecía que íbamos a tener que esperar otro tiempo prolongado para que Óscar Colchado le dedicara un nuevo libro a la ciudad de Chimbote, donde transcurrió gran parte de su niñez y juventud. Pero no ha sido así. Con la publicación de la novela Hombres de mar (Alfaguara, 2011), Colchado le confiere un lugar privilegiado al puerto ancashino convirtiéndolo en escenario principal de un universo temático basado en la actividad pesquera industrial. Así, alrededor de ésta, se mueven subuniversos complementarios como el de la actividad sindical, la prostitución, el trajín político, la experiencia estudiantil y la reciente presencia del narcotráfico, los cuales interactúan en un marco temporal que se extiende desde la pasada década del '70 (gobierno de Francisco Morales Bermúdez) hasta aproximadamente el año 2000, cuando se lleva a cabo en Lima la conocida Marcha de los Cuatro Suyos. Estas tres décadas de historia chimbotana, le sirven al autor para situar al puerto (tal como haría Arguedas 40 años 
atrás) en una suerte de arquetipo de lo que ocurre social y políticamente en el país durante el tiempo en que se desarrollan los hechos (por lo que se ha dicho que Hombres de mar es una continuación de El zorro de arriba y el zorro de abajo).

Pero además de este referente temático y espacial, el autor no deja de lado su costumbre de incluir elementos mitológicos de la zona, y la influencia de éstos sobre los hombres en tiempos actuales. Los logros técnicos, estilísticos y expresivos de Hombres de mar, nos llevan a creer que proyectan a nuestro escritor hacia un horizonte global, y brindan la certeza de que nos encontramos frente a una personalidad viva de la literatura peruana, por lo que solo resta esperar a que la historia, el tiempo y el pueblo hagan su trabajo: hacer de Colchado Lucio una nueva y verdadera figura de la tradición narrativa latinoamericana.

\section{PANORAMA HISTÓRICO DE CHIMBOTE, de Fernando Bazán Blass}

Luego de una larga carrera educacional, Fernando Bazán Blass se ha dedicado durante los últimos veinticinco años a una profunda investigación historiográfica de la provincia del Santa. Conocido es ya en el medio su libro varias veces reeditado Historia de Chimbote, así como otros que lo com-
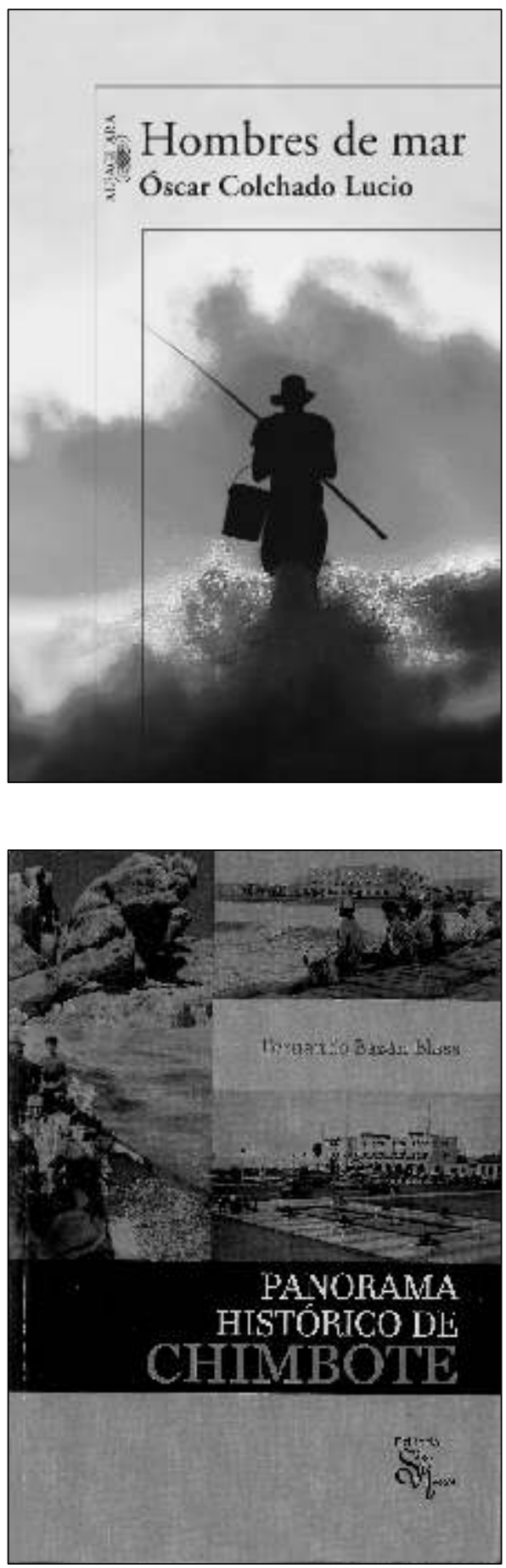
plementan: Historia del ferrocarril de Chimbote, Historia del movimiento democrático en Chimbote e Historia de la Comunidad de Indígenas de Chimbote y Coishco, y una gran cantidad de artículos publicados en medios escritos y virtuales.

Panorama histórico de Chimbote (San Marcos, 2012) es también un trabajo complementario con mucho de lo que, asumimos, se le quedó a Bazán en el tintero de la primera obra referida. En esta ocasión, aborda contenidos necesarios dentro del proceso cronológico de la provincia, como el turístico, el sindical, el religioso y el de los siempre anhelados proyectos de irrigación. De esta manera nos hallamos frente a un espectro historiográfico chimbotano cada vez más amplio, y Bazán Blass se convierte así en su más serio, esforzado y minucioso trabajador. Lo refrenda la amplia bibliografía que maneja, en la cual incluye documentos, mapas, fotografías, e incunables pertenecientes a los diversos archivos particulares y públicos del Perú.

\section{UN ZOMBI ILUSTRADO, de Freddy Arteaga Canessa}

La renovación narrativa en la provincia del Santa corre a toda velocidad, y esta primigenia entrega de Freddy Arteaga Canessa lo confirma. Un zombi ilustrado (Fondo Editorial de Nuevo Chimbote, 2012) es la reunión de veinte relatos con la factura técnica de lo diverso. Algunos asoman en forma de crónica, otros de cuentos clásicos y varios como memorias, epístolas o testimonios personales. Lo mismo ocurre con el lenguaje utilizado: Arteaga identifica muy bien la piscología de sus personajes y los hace monologar de modo sencillo aunque verosímil.

Pero lo diverso no solo discurre por allí, sino también por los juegos temporales a los que el autor se atreve: los textos nos trasladan a veces a diferentes momentos de la historia del mun-

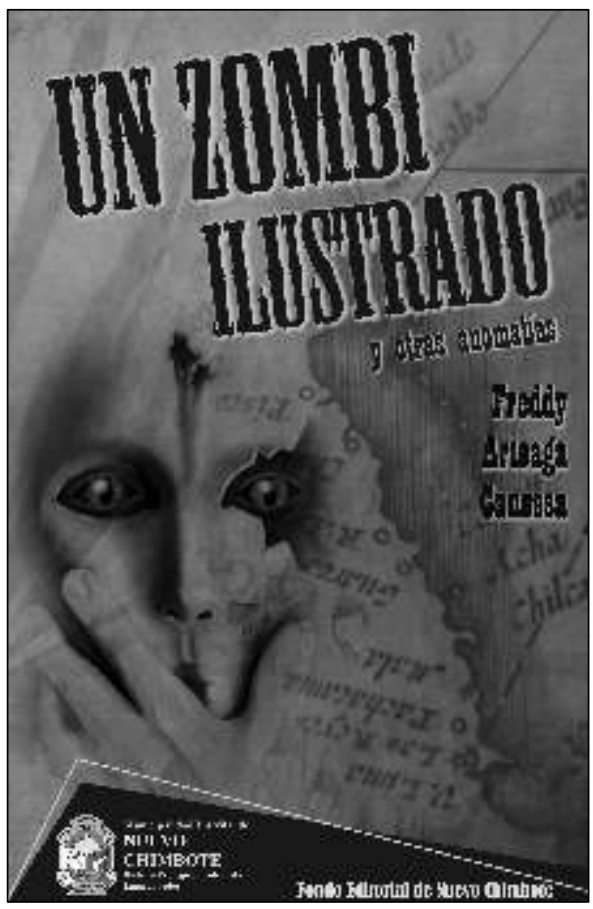


do, pero también se plantean desde las diversas edades que muestran sus protagonistas; de este modo, el reto es mayúsculo y, sin embargo, el pulso del escritor sale bien librado. El conjunto intenta, por otro lado, resolverse con temas sui géneris (a veces sobrenaturales) con relación a nuestro contexto, tendiendo de este modo a lo universal. Esperamos con sinceridad nuevas entregas de este joven narrador.

\section{DALESKA Y EL MAR, de Dante Lecca}

El conocido poeta chimbotano vuelve a las andadas con una plaqueta que reúne cinco textos (los que podrían ser uno solo dividido en el mismo número de títulos) dedicados a la joven Daleska Longobardi, señorita Nuevo Chimbote 2012. Las imágenes de Daleska y el mar (Ornitorrinco, 2012) son sencillas, audaces, pero no permiten que se pierda aquella calidad lírica a la que Lecca nos tiene acostumbrados.

La emoción expresiva es identificable si nos detenemos en el sentimiento de admiración de donde parte todo lo escrito. El poeta admira a la musa por sobre todas las cosas (a la mejor manera de Melgar con Silvia, o del propio Alighieri con Beatrice) y sin embargo no alcanza la altura de un ser amado como ocurre con éstas, sino de un ser admirado desde su belleza, deseado desde su esencia femenina. Daleska Longobardi es de carne y hueso, camina y respira entre nosotros como cualquier mortal, y sin embargo se nos ofrece la debida versión ensoñadora, la obligada categoría de divinidad, que el poeta necesita para lograr estos versos desenvueltos y vehementes surgidos de un recorrido que ocupa espacios, elementos y circunstancias identificables aunque vertidos adorablemente por esa mar infinita que es la palabra.

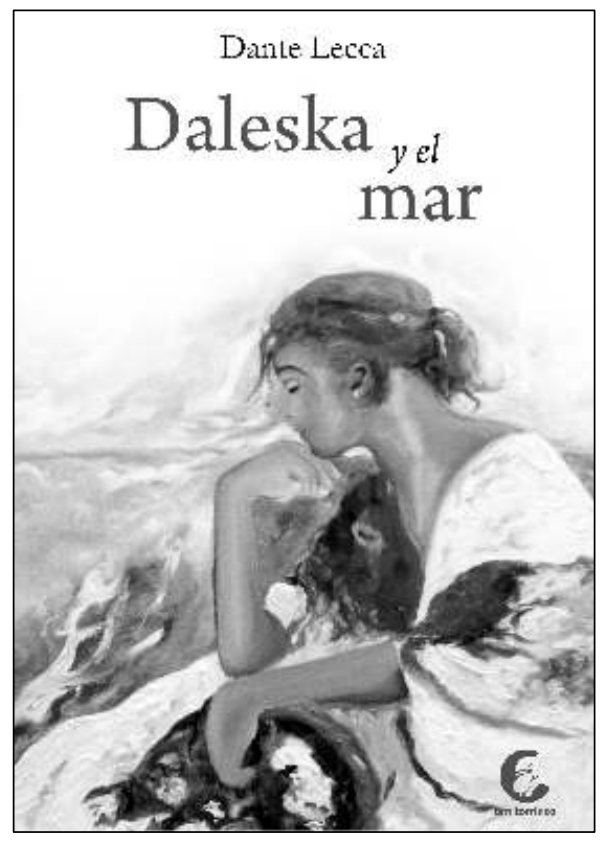

